\title{
The effect of pregnancy induced hypertension and multiple pregnancies on preterm birth in Ethiopia: a systematic review and meta-analysis
}

\author{
Getaneh Mulualem ${ }^{*}$, Amare Wondim ${ }^{1}$ and Abere Woretaw ${ }^{2}$
}

\begin{abstract}
Objective: This systematic review and meta-analysis aimed to estimate the overall pooled prevalence of preterm birth and the effect of pregnancy induced hypertension $(\mathrm{PIH})$ and multiple pregnancies on preterm birth in Ethiopia.

Result: A total of 9 studies with 27,119 participants were included in this systematic review and meta-analysis. The pooled prevalence of preterm birth among mothers who gave births in Ethiopia was found to be 13.32\% (95\% $\mathrm{Cl}=7.99,18.660)$. Preterm birth was found to be higher among mothers who had pregnancy induced hypertension with odds ratio of $4.69(95 \% \mathrm{Cl}=2.32,9.49)$ and multiple pregnancy with odds ratio of $2.40(95 \% \mathrm{Cl}=1.06,5.45)$ as compared to the counterparts. In subgroup analysis by region, the prevalence of preterm birth was found to be $12.63 \%(95 \% \mathrm{Cl}=3.26,22)$ in Amhara and $10.18 \%(95 \% \mathrm{Cl}=6.04,14.32)$ in Oromia region.
\end{abstract}

Keywords: Ethiopia, Multiple pregnancy, Pregnancy induced hypertension, Preterm birth

\section{Introduction}

Preterm birth is defined as babies born alive before 37 weeks of pregnancy is completed. Globally, every year, an estimated 15 million babies are born before 37 weeks of gestation of which $85 \%$ of the preterm births are concentrated in Africa and Asia [1,2]. Preterm birth is one of the major determinants of neonatal morbidity and mortality [3]. Worldwide, $27 \%$ of the direct leading cause of neonatal death is preterm birth; more than one million preterm newborns die annually [4].

Developmental immaturity affects a wide range of organ systems in preterm neonates. Preterm birth results in short term complications, such as respiratory distress syndrome, apnea and brain immaturity [5]. Many of them develop lifelong complications, like pneumonia, respiratory failure, cerebral palsy, neurological impairment,

\footnotetext{
*Correspondence: getanehmulua@gmail.com

${ }^{1}$ Department of Pediatrics and Child Health Nursing, School of Nursing, College of Medicine and Health Sciences, University of Gondar, P.O.BOX: 196, Gondar, Ethiopia

Full list of author information is available at the end of the article
}

mental retardation, visual and hearing impairments and poor health [6-10].

Around $75 \%$ of the preterm births result from spontaneous preterm labour. The remaining $25 \%$ are delivered for medical reasons [11]. The causes of preterm birth are multifactorial [12]. These may be history of pregnancy induced hypertension [13-17], premature rupture of membrane [14, 15, 17], placenta previa, abruption placenta [16], maternal depression symptoms [18], previous indicated preterm birth $[13,17]$, lung diseases, heavy work during pregnancy [13], multiple gestations [14, 16], urinary tract infections $[15,16]$, history of stillbirth, history of miscarriage [16], and inadequate antenatal visits $[16,17]$.

Use of alternative models of antenatal care [19], treating intra-uterine infections, improving maternal nutrition, maternal lifestyle modification [20], smoking cessation, reduction of non-medically indicated labour induction or caesarean delivery are common strategies used to reduce preterm birth [8]. In Ethiopia, even though there is a strong initiative in antenatal care service implementations [21], different studies show the 
prevalence of preterm birth. Therefore, this systematic review and meta-analysis will determine the effect of PIH and multiple pregnancies on preterm birth in Ethiopia.

\section{Main text \\ Methods \\ Protocol and registration}

This protocol has been registered with the International Prospective Register of Systematic Reviews (PROSPERO). The web address and the registration number of this systematic review and meta-analysis are https:// www.crd.york.ac.uk/PROSPERO and CRD42019118389 respectively.

\section{Reporting}

The preferred reporting items of systematic reviews and meta-analysis (PRISMA) guideline [22] was used to report the result of this study (Additional file 1).

\section{Inclusion and exclusion criteria}

In this study, articles which fulfilled the criteria, (1) observational studies including cohort, cross-sectional, and case-control studies; (2) articles that report the prevalence of preterm birth and/studies that report the association of pregnancy induced hypertension (PIH) and/multiple pregnancy) with preterm birth; (3) studies conducted in Ethiopia; (4) published and unpublished articles at any time; (5) studies which have been written by English, and (6) Studies conducted both at community or institution level were included. Conference papers, editorials, articles without full texts, trials, systematic reviews and meta-analyses, and qualitative studies were excluded.

\section{Outcome measurement}

Preterm birth is defined as babies born alive before 37 weeks of pregnancy is completed [2].

\section{Databases and searching strategy}

We searched all available articles with electronic databases including, PubMed, EMBASE, web of science, and Google scholar. Additionally, we searched using the reference list of included studies and the Ethiopian institutional research repository. Articles were searched using the following search terms: "preterm", "low gestational age", "preterm birth", "preterm delivery", "early delivery", "pregnancy induced hypertension", "hypertension", "preeclampsia", "eclampsia", "pregnancy", "multiple pregnancy", "twin pregnancy", "prevalence", "incidence", "predictors", "factors", "risk factors", and "Ethiopia". A searching string was developed using "AND" and "OR" BOOLEN operators. PubMed searching was done using this searching string (Additional file 2).

\section{Study selection and quality assessment}

First, all identified studies were imported to Endnote 7 citation manager. Second, duplicates were carefully removed. Third, two independent authors (GM and $\mathrm{AW}$ ) were screened and assessed the title and abstracts followed by full text assessment. Any disagreements between authors were solved by discussion and consensus. Fourth, Two investigators (GM and AW) assessed the quality of studies using the JBI quality appraisal criteria [23]. Any disagreements were solved by discussion and repeating the procedures. For assessing the quality, we used the JBI critical appraisal checklist adapted for cross-sectional, case-control, and cohort studies (Additional file 3) [23]. Studies considered low risk whenever fitted to $50 \%$ and or above quality assessment checklist criteria's.

\section{Data extraction}

After quality assessment, two independent authors (GM and AW) extracted the data in excel Microsoft spreadsheet. The extracted data items were, first author, year of publication, study area, region, design, population, sample size, prevalence of preterm birth, OR of PIH, and multiple pregnancies. Any disagreements were solved by discussion.

\section{Data analysis}

A weighted inverse variance random- effects model [24] was used. Subgroup analysis by region was done to estimate regional variations in the prevalence of preterm birth. The percentage of total variation between studies due to heterogeneity was assessed with $\mathrm{I}^{2}[25] . \mathrm{I}^{2}$ test statistics results of $25 \%, 50 \%$, and $75 \%$ were declared as low, moderate, and high heterogeneity, respectively [25]. Publication bias was assessed by funnel plot and Egger's test. Statistically significant publication bias was declared at P-value less than 0.05 . STATA version 11 statistical software was used for statistical analysis.

\section{Result}

\section{Search results}

On the whole, we searched 1435 articles from different data sources of which 1307 articles were from PubMed, 71 from Google scholar, 23 from EMBASE, 11 from web of science, 3 from reference lists of included studies, 7 from institutional research repositories, and 13 from Google. Ninety-seven articles were removed due to duplicates, 1277 due to irrelevant titles and abstracts, 24 due to study area (done in another country), and 10 due to study design. Twenty-seven articles were selected for the full text review of which 18 were excluded after the full text review. Finally, 9 studies 
were included in this systematic review and meta-analysis to estimate the effect of PIH and multiple pregnancies on preterm birth and pooled prevalence of preterm birth in Ethiopia (Fig. 1).

\section{Characteristics of included studies}

A total of 9 studies with 27, 119 participants were included in this systematic review and meta-analysis. Out of nine studies conducted, three [26-28] were from Amhara region, three [29-31] from Tigray, two [17, 32] from Oromia, and one [33] from Addis Abeba. Regarding the study design, 6 studies [26-28, 31-33] were cross-sectional, two [17, 30] case-control, and one [33] retrospective follow up. The highest prevalence of preterm birth was reported from Oromia (25.9\%) [32] and the lowest from Amhara region (4.4\%) [27] (Table 1).

\section{Quality of included studies}

Out of nine studies, six were assessed with JBI critical appraisal checklist for cross-sectional studies, two studies with a JBI critical appraisal for case-control, and one study with JBI checklist for cohort studies. None of the studies were excluded after quality assessment. The results were described in (Table 1 ).

\section{Meta-analysis}

A significant publication bias was not observed in this study. Hence, visual inspection of funnel plot was symmetrical, and Egger's regression P-value was 0.303 (Additional file 4).

\section{Prevalence of preterm birth}

Out of 9 studies, seven $[26-29,31-33]$ reported the prevalence of preterm birth considered in the meta-analysis to estimate the pooled prevalence of

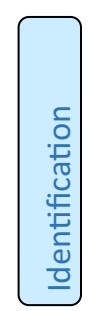

Articles identified with electronic databases searching $(\mathrm{n}=1341)$
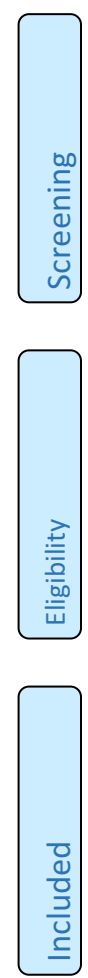

Articles identified though other sources $(n=94)$
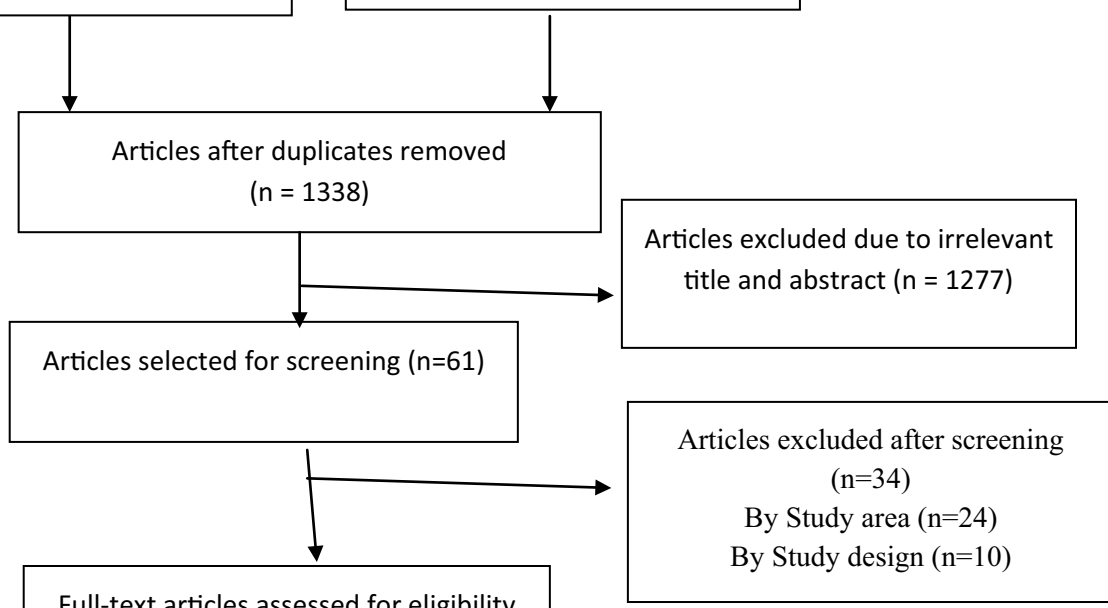

Full-text articles assessed for eligibility $(n=27)$

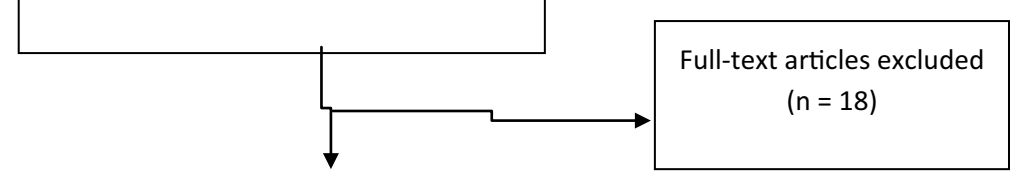

Studies included in quantitative synthesis (meta-analysis) $(n=9)$

Fig. 1 A PRISMA flow diagram of articles screening and process of selection 
Table 1 General characteristics of included studies that report the prevalence of preterm and/its association with pregnancy induced hypertension and multiple pregnancy

\begin{tabular}{|c|c|c|c|c|c|c|c|}
\hline $\begin{array}{l}\text { Author/year } \\
\text { of publication }\end{array}$ & Study area & Region & Study design & Study population & Sample size & Prevalence (\%) & Result of quality \\
\hline $\begin{array}{l}\text { Mengesha et al./2016 } \\
\text { [29] }\end{array}$ & Hospital & Tigray & Cohort & Mothers gave birth & 1152 & 6 & Low risk \\
\hline $\begin{array}{l}\text { Gebresillasie/2016 } \\
\text { [27] }\end{array}$ & GondarTown & Amhara & Cross-sectional & Mothers gave birth & 540 & 4.4 & Low risk \\
\hline $\begin{array}{l}\text { Deressa et al./2018 } \\
\text { [33] }\end{array}$ & Addis Abeba Hospital & Addis Abeba & Cross sectional & Mothers gave birth & 23,115 & 16.5 & Low risk \\
\hline Bekele et al./2015 [26] & Debremarkos Town & Amhara & Cross sectional & Mothers gave birth & 422 & 11.6 & Low risk \\
\hline $\begin{array}{l}\text { Adhena et al./2017 } \\
\text { [31] }\end{array}$ & Shirie Suhul Hospital & Tigray & Cross sectional & Mothers gave birth & 425 & 8.7 & Low risk \\
\hline Sakata et al./2017 [28] & $\begin{array}{l}\text { Gondar University } \\
\text { Hospital }\end{array}$ & Amhara & Cross sectional & Mothers gave birth & 325 & 22.5 & Low risk \\
\hline Bekele et al./2017 [32] & Jimma Hospital & Oromia & Cross sectional & Mothers gave birth & 220 & 25.9 & Low risk \\
\hline $\begin{array}{l}\text { Abaraya et al./2018 } \\
\text { [17] }\end{array}$ & $\begin{array}{l}\text { Jimma University } \\
\text { Hospital }\end{array}$ & Oromia & Case control & Mothers gave birth & 656 & NA & Low risk \\
\hline $\begin{array}{l}\text { Teklay } \\
\text { et al./2017/2018 } \\
\text { [30] }\end{array}$ & Mekelle Hospital & Tigray & Case control & Mothers gave birth & 264 & NA & Low risk \\
\hline
\end{tabular}

preterm birth in Ethiopia. The pooled prevalence of preterm birth in Ethiopia was found to be $13.32 \%$ (95\% $\mathrm{CI}=7.99,18.66 ; \mathrm{I}^{2}=98.5 \% ; \mathrm{P}=0.000$ ) (Fig. 2). Egger's regression test $\mathrm{P}$-value $=0.303$.

We performed a subgroup analysis by region. Consequently, the pooled prevalence by region was $12.63 \%$ (95\% $\left.\mathrm{CI}=3.26,22 ; \mathrm{I}^{2}=96.7 \% ; \mathrm{P}=0.000\right)$ for Amhara and $10.18 \%\left(95 \% \mathrm{CI}=6.04,14.32 ; \mathrm{I}^{2}=93.9 \% ; \mathrm{P}=0.000\right)$ for Oromia (Additional file 5).

\section{The association of PIH and multiple pregnancies with preterm birth}

To further explore the association between PIH and preterm birth, five studies [17, 27, 30, 32, 33] reported extractable data on preterm birth among mothers with $\mathrm{PIH}$ and with no PIH. One study [33] is excessively influential, and not considered in the meta-analysis. In the current study, preterm birth was 4.69 times higher 4.69 (95\% $\mathrm{CI}=2.32$, 9.49; $\mathrm{I}^{2}=67.6 \% ; \mathrm{P}=0.026$ ) among mothers who had pregnancy induced hypertension compared to mothers with no PIH (Additional file 6). Moreover, the association between preterm birth and multiple pregnancy was explored. Out of 9 studies, five $[17,28,30,32,33]$ reported sufficient data to calculate the odds ratio. Consequently, preterm birth among multiple pregnancies was found to be 2.4 times higher 2.40 (95\% CI $\left.=1.06,5.45 ; \mathrm{I}^{2}=85.6 \% ; \mathrm{P}=0.000\right)$ compared to single pregnancy (Additional file 7).

\section{Discussion}

Despite the advancement of preterm birth management, the proportion of preterm birth and its being a major and direct cause of neonatal mortality is still high among delivering mothers [34]. So far, there is no previous systematic reviews/meta-analyses that have examined the national estimate of preterm birth in Ethiopia. The aim of this systemic review and meta-analysis was to assess the effect of pregnancy induced hypertension and multiple pregnancy on preterm birth in the country.

Although Ethiopia was not mentioned among the top ten countries with the highest rates of preterm birth per 100 live births in the world, inconsistency of findings was reported with regard to the problem. The overall pooled prevalence of preterm birth on this study was found to be 13.32 (95\% CI 7.99, 18.66). This finding is lower than that of Kenya (20.2\%) [35] and (18.3\%) [14], 18.01\% in India [36], 14.2\% in Tanzania [16], 16.81\% in Pakistan [37] but higher than 12.8\% in Jordan [38], 12.3\% in Brazil [39], and 9.2\% in Iran [40]. The high prevalence of preterm birth in Ethiopia could be due to risk factors, like the occurrence of infections during pregnancy, several lifestyle conditions (stress, strenuous work, standing work), short interpregnancy interval, and low body mass index thought to be high although half of the preterm births occur idiopathically [41].

Subgroup analysis revealed that there was a significant variation among regions. Preterm birth in Amhara region was higher than that of Tigray. The difference might be 


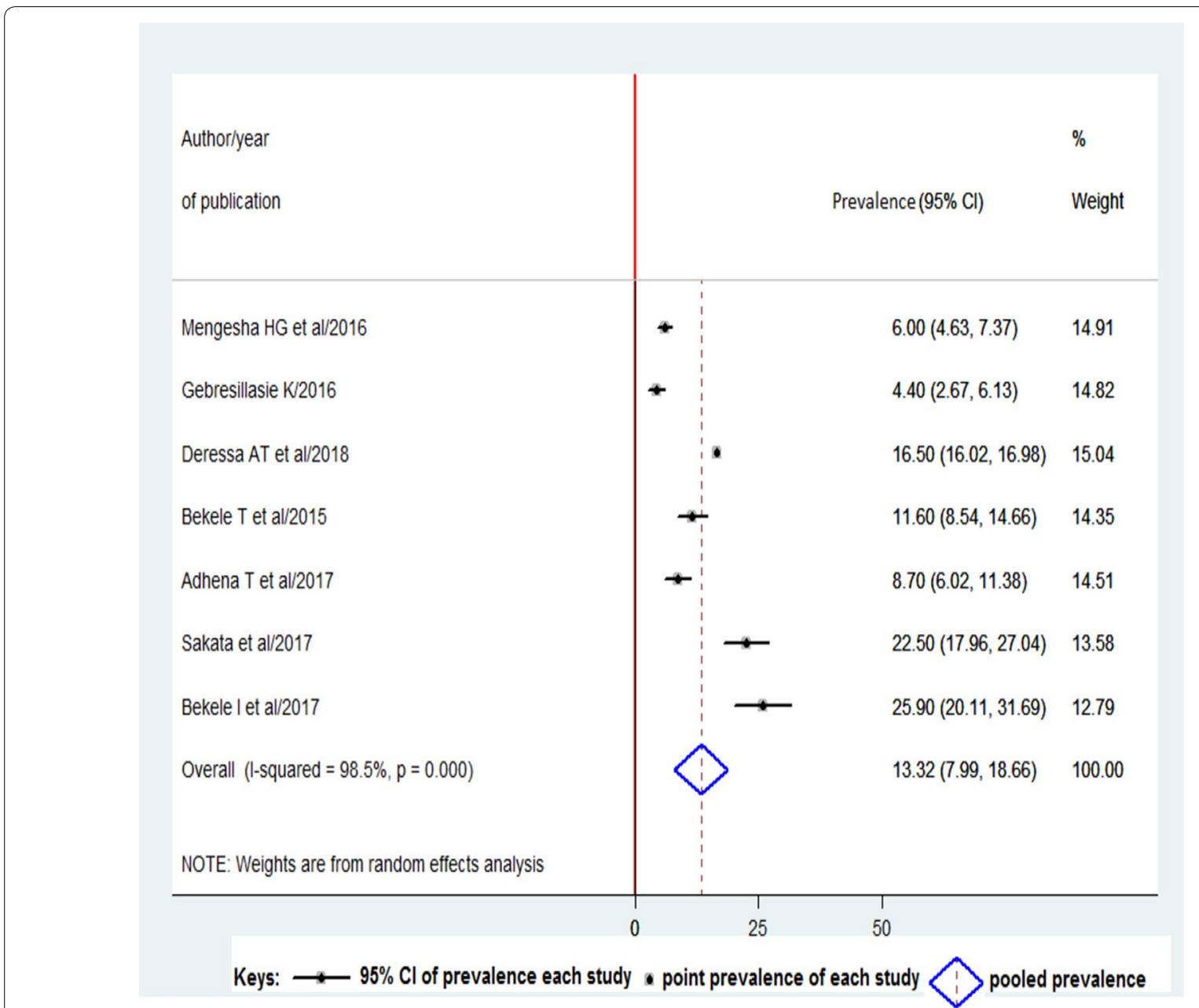

Fig. 2 Forest plot of the prevalence of preterm birth with 95\% Cl. The midpoint and length of each segment indicated the prevalence and $95 \%$ confidence interval. The diamond shape revealed the pooled prevalence

because mothers in Tigray had health setups, infrastructures, and better accesses to healthcare settings that have the potential to reduce preterm birth than mothers in Amhara.

Concerning the predictors, enormous risks, including demographic, social, and medical were identified [14, 16, 39, 42]. Among the risks PIH was in increasing trend [43]. In this study, mothers with PIH were nearly 4.7 times more likely to give preterm births than those who had no hypertension $(\mathrm{OR}=4.69 ; 95 \% \mathrm{CI}=2.32,9.49)$. This finding is in line with those of studies conducted in Tanzania [16], Kenya [35], and report from the United Kingdom [44]. This might be due to the fact that PIH could cause vascular damage to the placenta, which induces the oxytocin receptors, resulting in preterm labor and delivery. Besides, hypertension decreases the utero-placental blood floor, which leads to intrauterine growth restriction that causes preterm delivery.
The odds of a mother with multiple pregnancies were 2.4 times more likely to give preterm birth than mothers with single pregnancies (OR $=2.40 ; 95 \% \mathrm{CI} 1.06,5.45)$. The finding is supported by those of cohort studies, and systematic reviews in China [45], Tanzania [16], and Kenyatta National hospital, Kenya [14]. This is probably due to the over distension of the uterus by multiple pregnancies which stimulate early labour leading to preterm delivery. Moreover, other complications, like pre-eclampsia, and polyhydramnios are more likely to occur with multiple gestations and contribute to iatrogenic preterm birth.

\section{Conclusion}

Preterm birth in Ethiopia is a significant problem. Though the determinants of preterm birth are multifactorial, PIH and multiple pregnancies remained a major contributing factor to the risk of preterm birth. 
Preconception counseling and antenatal care to facilitate timely management of $\mathrm{PIH}$, more specially controlling hypertension is very important to maintain blood flow to the fetus. Improving health care quality delivered to pregnant women may reduce risk factors for preterm delivery.

\section{Limitations}

Strength of this review: Since there has been no similar previous study, this review and meta-analysis showed the national pooled image of preterm birth in Ethiopia and the effect of pregnancy induced hypertension and multiple pregnancy on preterm birth. Strictly following PRISMA guide line and Joanna Briggs Institute MetaAnalysis of Statistics Assessment and Review Instrument (JBI-MAStARI) during critical appraisal is the additional strength of this systemic review and meta-analysis.

The search strategy was limited to articles published in English, and this could lead to reporting bias. Relevant predictors might have been missed; hence, future reviews should consider other factors of preterm birth to explore the inquiry more deeply on subject of inquiry. Furthermore, presence of high statistical heterogeneity among studies conducted on preterm birth were considered as limitation of this review.

\section{Additional files}

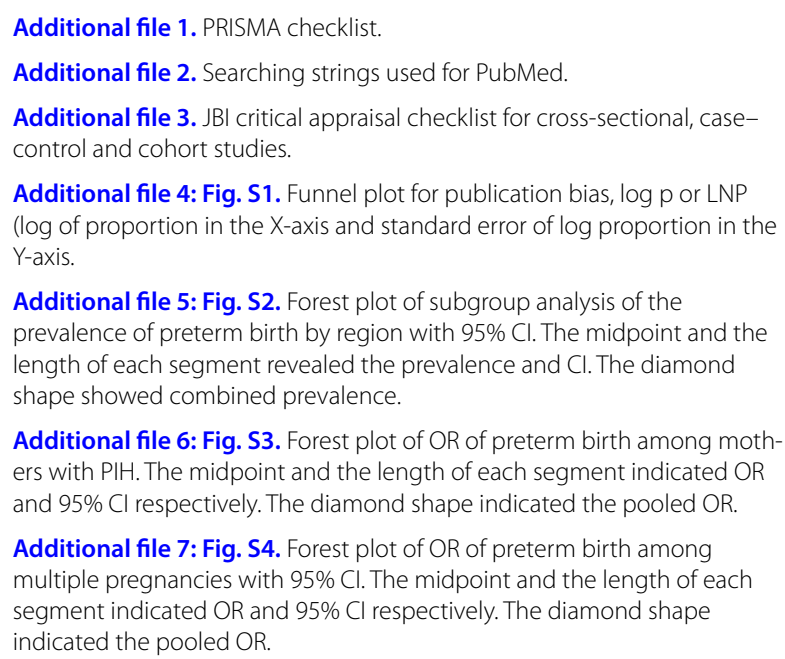

Additional file 5: Fig. S2. Forest plot of subgroup analysis of the prevalence of preterm birth by region with $95 \% \mathrm{Cl}$. The midpoint and the length of each segment revealed the prevalence and $\mathrm{Cl}$. The diamond shape showed combined prevalence.

Additional file 6: Fig. S3. Forest plot of OR of preterm birth among mothers with PIH. The midpoint and the length of each segment indicated OR and $95 \% \mathrm{Cl}$ respectively. The diamond shape indicated the pooled OR.

Additional file 7: Fig. S4. Forest plot of OR of preterm birth among multiple pregnancies with $95 \% \mathrm{Cl}$. The midpoint and the length of each segment indicated $\mathrm{OR}$ and $95 \% \mathrm{Cl}$ respectively. The diamond shape indicated the pooled OR.

\section{Abbreviations}

Cl: confidence interval; JBI: Joanna Briggs Institute; OR: odds ratio; PIH: pregnancy induced hypertension.

\section{Authors' contributions}

GM conceived and designed the study. GM, AbW and AmW established the search strategy, extract the data, assess the quality of included study, analysis and finally wrote the review. All authors had prepared the manuscript. All authors read and approved the final manuscript.

\section{Author details}

${ }^{1}$ Department of Pediatrics and Child Health Nursing, School of Nursing, College of Medicine and Health Sciences, University of Gondar, P.O.BOX: 196, Gondar, Ethiopia. ${ }^{2}$ Department of Medical Nursing, School of Nursing, College of Medicine and Health Sciences, University of Gondar, P.O.BOX: 196, Gondar, Ethiopia.

\section{Acknowledgements}

Our special gratitude goes to the authors of included studies which help us to do this systematic review and meta-analysis.

\section{Competing interests}

The authors declare that they have no competing interests.

\section{Availability of data and materials}

All data generated or analyzed during study included in this systematic review and meta-analysis.

\section{Consent for publication}

Not applicable.

\section{Ethics approval and consent to participate}

Not applicable because no primary data collected.

\section{Funding}

This research received no specific grants from funding agency.

\section{Publisher's Note}

Springer Nature remains neutral with regard to jurisdictional claims in published maps and institutional affiliations.

Received: 20 December 2018 Accepted: 11 February 2019

Published online: 18 February 2019

\section{References}

1. Beck S, Wojdyla D, Say L, Betran AP, Merialdi M, Requejo JH, et al. The worldwide incidence of preterm birth: a systematic review of maternal mortality and morbidity. Bull World Health Organ. 2010;88:31-8.

2. Preterm birth. World Health Organization. 2018. http://www.who.int/ news-room/fact-sheets/detail/preterm-birth.

3. Berkowitz GS, Papiernik E. Epidemiology of preterm birth. Epidemiol Rev. 1993;15(2):414-43.

4. Lawn JE, Gravett MG, Nunes TM, Rubens CE, Stanton C. Global report on preterm birth and stillbirth (1 of 7): definitions, description of the burden and opportunities to improve data. BMC Pregnancy Childbirth. 2010;10(1):S1.

5. Mandy GT. Short-term complications of the preterm infant.

6. Butler AS, Behrman RE. Preterm birth: causes, consequences, and prevention. New York: National Academies Press; 2007.

7. Mandy GT. Long-term complications of the preterm infant.

8. Chang HH, Larson J, Blencowe H, Spong CY, Howson CP, Cairns-Smith S, et al. Preventing preterm births: analysis of trends and potential reductions with interventions in 39 countries with very high human development index. Lancet. 2013;381(9862):223-34.

9. Hibbard JU, Wilkins I, Sun L, Gregory K, Haberman S, Hoffman M, et al. Respiratory morbidity in late preterm births. JAMA. 2010;304(4):419.

10. Randis TM. Complications associated with premature birth. Virtual Mentor. 2008;10(10):647

11. Stock SJ, Ismail K. Which intervention reduces the risk of preterm birth in women with risk factors. BMJ. 2016;355:15206.

12. Simmons LE, Rubens CE, Darmstadt GL, Gravett MG. Preventing preterm birth and neonatal mortality: exploring the epidemiology, causes, and interventions. Seminars in perinatology. New York: Elsevier; 2010.

13. Meis PJ, Goldenberg RL, Mercer BM, lams JD, Moawad AH, Miodovnik $M$, et al. The preterm prediction study: risk factors for indicated preterm births. Am J Obstet Gynecol. 1998;178(3):562-7. 
14. Wagura P, Wasunna A, Laving A, Wamalwa D. Prevalence and factors associated with preterm birth at kenyatta national hospital. BMC Pregnancy Childbirth. 2018;18(1):107.

15. Butali A, Ezeaka C, Ekhaguere O, Weathers N, Ladd J, Fajolu I, et al. Characteristics and risk factors of preterm births in a tertiary center in Lagos, Nigeria. Pan Afr Med J. 2016;24:1.

16. Temu TB, Masenga G, Obure J, Mosha D, Mahande MJ. Maternal and obstetric risk factors associated with preterm delivery at a referral hospital in northern-eastern Tanzania. Asian Pac J Reprod. 2016:5(5):365-70.

17. Abaraya M, Seid SS, Ibro SA. Determinants of preterm birth at Jimma University Medical Center, southwest Ethiopia. Pediatric Health Med Ther. 2018;9:101.

18. Orr ST, James SA, Blackmore Prince C. Maternal prenatal depressive symptoms and spontaneous preterm births among African-American women in Baltimore, Maryland. Am J Epidemiol. 2002;156(9):797-802.

19. Turienzo CF, Sandall J, Peacock JL. Models of antenatal care to reduce and prevent preterm birth: a systematic review and meta-analysis. BMJ Open. 2016;6(1):e009044.

20. Newnham JP, Dickinson JE, Hart RJ, Pennell CE, Arrese CA, Keelan JA. Strategies to prevent preterm birth. Front Immunol. 2014;5:584

21. Gebreyohannes Y, Ararso D, Mengistu F, Abay S, Hadis M. Improving antenatal care services utilization in Ethiopia: an evidence-based policy brief.

22. Liberati A, Altman DG, Tetzlaff J, Mulrow C, Gøtzsche PC, loannidis JP, et al. The PRISMA statement for reporting systematic reviews and meta-analyses of studies that evaluate health care interventions: explanation and elaboration. PLoS Med. 2009;6(7):e1000100.

23. Institute JB. Joanna Briggs Institute critical appraisal tools. 2017.

24. Borenstein M, Hedges LV, Higgins JP, Rothstein HR. A basic introduction to fixed-effect and random-effects models for meta-analysis. Res Synth Methods. 2010;1(2):97-111.

25. Higgins JP, Thompson SG, Deeks JJ, Altman DG. Measuring inconsistency in meta-analyses. BMJ. 2003;327(7414):557.

26. Bekele T, Amanon A, Gebreslasi K. Pre-term birth and associated factors among mothers who gave birth in Debremarkos town health institutions, 2013 institutional based cross sectional study. Gynecol Obstet. 2015;5(5):292-7.

27. Gebreslasie K. Preterm birth and associated factors among mothers who gave birth in Gondar Town Health Institutions. Adv Nurs. 2016;2016:5.

28. Sakata Maru WT, Abeju M, Demelash W. Prevalence and associated factors of preterm among mothers who gave births at university of Gondar compressive specialized referral Hospital, North Gondar Ethiopia. 2018.

29. Mengesha HG, Lerebo WT, Kidanemariam A, Gebrezgiabher G, Berhane Y. Pre-term and post-term births: predictors and implications on neonatal mortality in Northern Ethiopia. BMC Nurs. 2016;15(1):48.

30. Teklay G, Teshale T, Tasew H, Mariye T, Berihu H, Zeru T. Risk factors of preterm birth among mothers who gave birth in public hospitals of central zone, Tigray, Ethiopia: unmatched case-control study 2017/2018. BMC Res Notes. 2018;11(1):571.
31. Tesfaye A, Abera H, Brhan G. Assessment of magnitude and associated factors of adverse birth outcomes among deliveries at Suhul Hospital Shire, Tigray, Ethiopia from september, 2015 to february, 2017. Biomed J Sci \& Tech Res. 2017;1(7):2017. BJSTR. MS.ID.000619.

32. Bekele I, Demeke T, Dugna K. Prevalence of preterm birth and its associated factors among mothers delivered in Jimma university specialized teaching and referral hospital, Jimma Zone, Oromia Regional State, South West Ethiopia. J Women's Health Care. 2017;6:356.

33. Deressa AT, Cherie A, Belihu TM, Tasisa GG. Factors associated with spontaneous preterm birth in Addis Ababa public hospitals, Ethiopia: cross sectional study. BMC Pregnancy Childbirth. 2018;18(1):332.

34. Tigist Bekele AA. Preterm birth and associated factors among mothers who gave birth in Debremarkos Town Health Institutions, 2013 institutional based cross sectional study. Gynecol Obstetr. 2015;5(5):1-5.

35. Okube OT, Sambu LM. Determinants of preterm birth at the postnatal ward of Kenyatta National Hospital, Nairobi, Kenya. Open J Obstetr Gynecol. 2017;7(09):973.

36. Shetty MB, Krupa B, Malyala M, Swarup A, Pathadan DS, Pocha S. Preterm birth: associated risk factors and outcome in tertiary care center. Int J Reprod Contracept Obstetr Gynecol. 2017;6(8):3271-4.

37. Hanif A, Ashraf T, Waheed K, Sajid MR, Guler N, Pervaiz MK. Prevalence of preterm birth in Pakistan: a systematic review and meta-analysis. Ann King Edward Med Univ. 2017;23:2.

38. Mohammad K, Abu Dalou A, Kassab M, Gamble J, Creedy DK. Prevalence and factors associated with the occurrence of preterm birth in I rbid governorate of J ordan: a retrospective study. Int J Nurs Pract. 2015;21(5):505-10.

39. Passini R Jr, Cecatti JG, Lajos GJ, Tedesco RP, Nomura ML, Dias TZ, et al. Brazilian multicentre study on preterm birth (EMIP): prevalence and factors associated with spontaneous preterm birth. PLOS ONE. 2014;9(10):e109069.

40. Vakilian K, Ranjbaran M, Khorsandi M, Sharafkhani N, Khodadost M. Prevalence of preterm labor in Iran: a systematic review and meta-analysis. Int J Reprod BioMed. 2015;13(12):743.

41. Mohsenzadeh A, Saket S, Karimi A. Prevalence of preterm neonates and risk factors. Iran J Neonatol. 2011;2(1):38-42.

42. Meis PJ, Michielutte R, Peters TJ, Wells HB, Sands RE, Coles E, et al. Factors associated with preterm birth in Cardiff, Wales: II Indicated and spontaneous preterm birth. Am J Obstetr Gynecol. 1995;173(2):597-602.

43. Mekonnen TAG. Pregnacy induced h.pdf. J Pregnancy Child Health. 2017;4(5):1-4.

44. Platt M. Outcomes in preterm infants. Public Health. 2014;128(5):399-403.

45. Lu L, Qu Y, Tang J, Chen D, Mu D. Risk factors associated with late preterm births in the underdeveloped region of China: a cohort study and systematic review. Taiwanese J Obstetr Gynecol. 2015;54(6):647-53.

\footnotetext{
Ready to submit your research? Choose BMC and benefit from:

- fast, convenient online submission

- thorough peer review by experienced researchers in your field

- rapid publication on acceptance

- support for research data, including large and complex data types

- gold Open Access which fosters wider collaboration and increased citations

- maximum visibility for your research: over $100 \mathrm{M}$ website views per year
}

At BMC, research is always in progress.

Learn more biomedcentral.com/submissions 